\title{
Surface modification of carbon dots with tetraalkylammonium moieties for fine tuning their antibacterial activity
}

Elizaveta Sviridova ${ }^{1}$, Alexandre Barras $^{2}$, Evgenii Plotnikov ${ }^{1}$, Antonio Di Martino ${ }^{1}$, Dominique Deresmes $^{2}$, Ksenia Nikiforova ${ }^{1}$, Marina Trusova ${ }^{1}$, Sabine Szunerits ${ }^{2}$, Olga Guselnikova ${ }^{1,3}$, Pavel Postnikov $^{1,} 3^{*}$, Rabah Boukherroub ${ }^{2 *}$

1. Research School of Chemistry and Applied Biomedical Sciences, Tomsk Polytechnic University, 634050 Tomsk, Russian Federation

2. Univ. Lille, CNRS, Centrale Lille, Univ. Polytechnique Hauts-de-France, IEMN, UMR CNRS 8520, F-59000 Lille, France

3. Department of Solid-State Engineering, University of Chemistry and Technology, 16628 Prague, Czech Republic

Corresponding authors:

Pavel Postnikov, Tel. +79039136029 (postnikov@tpu.ru);

Rabah Boukherroub, Tel. +330362531724 (rabah.boukherroub@ univ-lille.fr) 


\begin{abstract}
In this contribution, we report a facile functionalization method of carbon dots (CDs) by tetraalkylammonium moieties using diazonium chemistry to improve their antibacterial activity against Gram-positive and Gram-negative bacteria. CDs were modified by novel diazonium salts bearing tetraalkylammonium moieties (TAA) with different alkyl chains (C2, C4, C9, C12) for the optimization of antibacterial activity. The functionalized CDs were characterized by X-ray photoelectron spectroscopy (XPS), Fourier-transform infrared (FTIR) spectroscopy, ultravioletvisible (UV-vis) absorption spectrophotometry and fluorescence spectroscopy to confirm the covalent binding of TAA onto the CDs' surface. Variation of the alkyl chain allows to reach the strongest antibacterial effect for CDs-C9 towards Gram-positive S. aureus (MIC 3.09 $\pm 1.10 \mu \mathrm{g} \mathrm{mL}^{-1}$ ) and Gramnegative E. coli (MIC 7.93 $\pm 0.17 \mu \mathrm{g} \mathrm{mL}^{-1}$ ) bacteria. In addition, the antibiofilm properties of the CDsC9 were assessed; full biofilm inhibition was achieved after $6 \mathrm{~h}(64 \mu \mathrm{g} \mathrm{mL}-1)$ and $2 \mathrm{~h}\left(128 \mu \mathrm{g} \mathrm{mL} \mathrm{m}^{-1}\right)$ treatment for $S$. aureus biofilm and $>60 \%$ suppression of biofilm mass after $6 \mathrm{~h}\left(128 \mu \mathrm{g} \mathrm{mL} \mathrm{m}^{-1}\right)$ for $E$. coli biofilm. CDs-C9 demonstrated good biocompatibility on mouse fibroblast (NIH/3T3), HeLa and U-87 MG cell lines for concentrations up to $256 \mu \mathrm{g} \mathrm{mL}$. Collectively, our work highlights the correlation between the surface chemistry of CDs and their antimicrobial performance.
\end{abstract}

Keywords: Carbon dots; diazonium chemistry; tetraalkylammonium salts; antibacterial activity; biofilms 


\section{Introduction}

There is a global challenge in the overcoming of bacterial resistance caused by increasingly ineffectiveness of common antibiotic molecules - in 2019, only 6 of 32 clinical developed antibiotics were classified as innovative [1]. In most cases, all the current antibiotics are not able to treat bacteria biofilms that are responsible for causing a broad range of chronic diseases [2]. Therefore, there is an urgent need to develop new alternative antimicrobial agents to prevent extending drug-resistance and biofilm-related infections.

In the last decade, great attention has been focused on the development of nanomaterials with antimicrobial properties including antibiofilm characteristics [3-5]. Among the various nanoparticles used as antimicrobial agents, carbon dots (CDs) are highly attractive due to their structural features associated with "zero-dimensional" size. CDs can be readily prepared by environmentally-frie ndly and low-cost methods. Particularly important is that CDs form stable aqueous suspensions and are non-toxic nanomaterials, especially in comparison with metal nanoparticles [6]. These features make CDs one of the close-to-perfect platforms for wide applications in the healthcare field.

The application of CDs as antibacterial agents is often limited by the low activity of pristine material. In order to enhance the efficacy of antibacterial treatment, the implementation of special synthetic or post-synthetic modification procedures is required [7,8]. A widespread method for the synthesis of antibacterial active CDs is based on the solvothermal treatment of nitrogen-rich feedstock [9-14]. All these N-containing precursors enhance the affinity to the bacteria membrane and further killing via electrostatic/hydrophobic interactions, generation of reactive oxygen species (ROS) or DNA/RNA damage $[12,15]$. Nevertheless, the solvothermal approaches do not allow to fine tune the surface properties and predict the properties of the produced CDs.

A more careful control of the surface properties and functionality can be achieved using surface modification methods [9]. Among the different functionalization schemes [16-18], diazonium chemistry is highly appealing owing to the high reactivity of diazonium salts, versality of chemical structure and formation of strong covalent bonds with the surface [19-22]. CDs can be readily functionalized by aryl radicals generated from appropriate diazonium salts, which allow to introduce specific surface properties [23,24]. Unfortunately, the diazonium surface chemistry has been widely applied for the modification of surfaces for sensing related aspects [25,26] as well for stabilization of graphene suspensions [27,28], but not for endowing nanomaterials with antibacterial properties $[25,26,29]$. 
In this contribution, we propose a versatile approach for the surface modification of CDs by novel diazonium salts bearing tetraalkylammonium moieties (TAA) of different alkyl chain lengths. Variation of the alkyl chain length allows to establish a relationship between the structure of surface functional groups and antibacterial performance for the preparation of effective antibacterial agents for both Gram-positive (Staphylococcus aureus) and Gram-negative (Escherichia coli) bacteria and their biofilms. To the best of our knowledge, this study represents the first report on CDs functionalization with diazonium salts bearing quaternary ammonium moieties with varying alkyl chain lengths for antibacterial and antibiofilm applications, opening more opportunities for the application of CDs in the field of biomedicine.

\section{Experimental part}

\subsection{Synthesis of amine-functionalized carbon dots}

The carbon dots (CDs) were synthesized following a slightly modified method reported in [16]. In brief, citric acid $(2.1 \mathrm{~g})$ and ethylenediamine $(670 \mu \mathrm{L})$ were dissolved in Milli-Q water $(20 \mathrm{~mL})$. Then, the solution was transferred in a $30 \mathrm{~mL}$ reaction vessel of a microwave reactor (Monowave 450 , Anton-Paar). A total of $2 \mathrm{~min}$ was required to elevate the temperature of the reaction vessel up to $200^{\circ} \mathrm{C}$ and maintained at this temperature for $5 \mathrm{~min}$ and then cooled to room temperature. The resulting solution was dialyzed in DI water through a dialysis membrane (Biotech CE $\mathrm{N}^{\circ} 131093$, MWCO $=500-1000 \mathrm{Da}$ ) for $24 \mathrm{~h}$ with changing MQ water every $3 \mathrm{~h}$ in order to remove unreacted small molecules. Then, a dry mass of $200 \mu \mathrm{L}$ solution was weighted by microbalance (XPR6UD5, Mettler Toledo) for the estimation of concentration.

\subsection{Modification of carbon dots with diazonium salts (CDs-C2, CDs-C4, CDs-C9 and CDs-C12)}

A solution of freshly synthesized CDs $\left(1 \mathrm{~mL}, 2 \mathrm{mg} \mathrm{mL}^{-1}\right)$ in water was mixed with methanol (water for CDs-C2) solution of ADT-N $\mathrm{N}^{+}(\mathrm{Alk})_{3}\left(1 \mathrm{~mL}, 12 \mathrm{mg} \mathrm{mL}^{-1}\right)$, ultrasonicated for $1 \mathrm{~h}$ and stirred for $3 \mathrm{~h}$ at room temperature. Then, the desired product (CDs-C2, CDs-C4, CDs-C9 and CDs-C12) was purified by dialysis against MQ water during $24 \mathrm{~h}$ using $3.5 \mathrm{kDa}$ regenerated cellulose membrane [20].

CDs-C4, CDs-C9 and CDs-C12 were additionally purified twice for removing unreacted diazonium salts by centrifugation (8000 rpm, $20 \mathrm{~min}$ ) after dialysis and dissolution in water prior to lyophilization. 


\section{Results and discussion}

\subsection{Synthesis and characterization of CDs, CDs-C2, CDs-C4, CDs-C9 and CDs-C12}

In the first stage, we synthesized arenediazonium tosylates (ADT- $\left.{ }^{+} \mathrm{Alk}_{3}\right)$ bearing different alkyl moieties (ethyl (C2), butyl (C4), nonyl (C9) and dodecyl (C12)) with the aim to estimate and clarify the influence of the alkyl chain length on antibacterial properties (Figure 1). The synthesis started from the commercially available 4-nitrobenzyl bromide precursor, followed by alkylation with triethylamine (formation of the corresponding triethylammonium salt) or dimethylamine. The $\mathrm{N}, \mathrm{N}$ dimethyl- $N$-(4-nitrobenzyl)amine was subjected to a second alkylation using appropriate alkyl bromide to yield tetraalkylammonium salts. The simple reduction of $\mathrm{NO}_{2}$ group by $\mathrm{Zn}$-powder in formic acid led to the formation of the desired amine, which was diazotized in the presence of 4toluenesulfonic acid. The isolated salts ADT-C2, ADT-C4, ADT-C9 and ADT-C12 showed enhanced stability at storage and can be used during at least 3 months after the preparation [30].

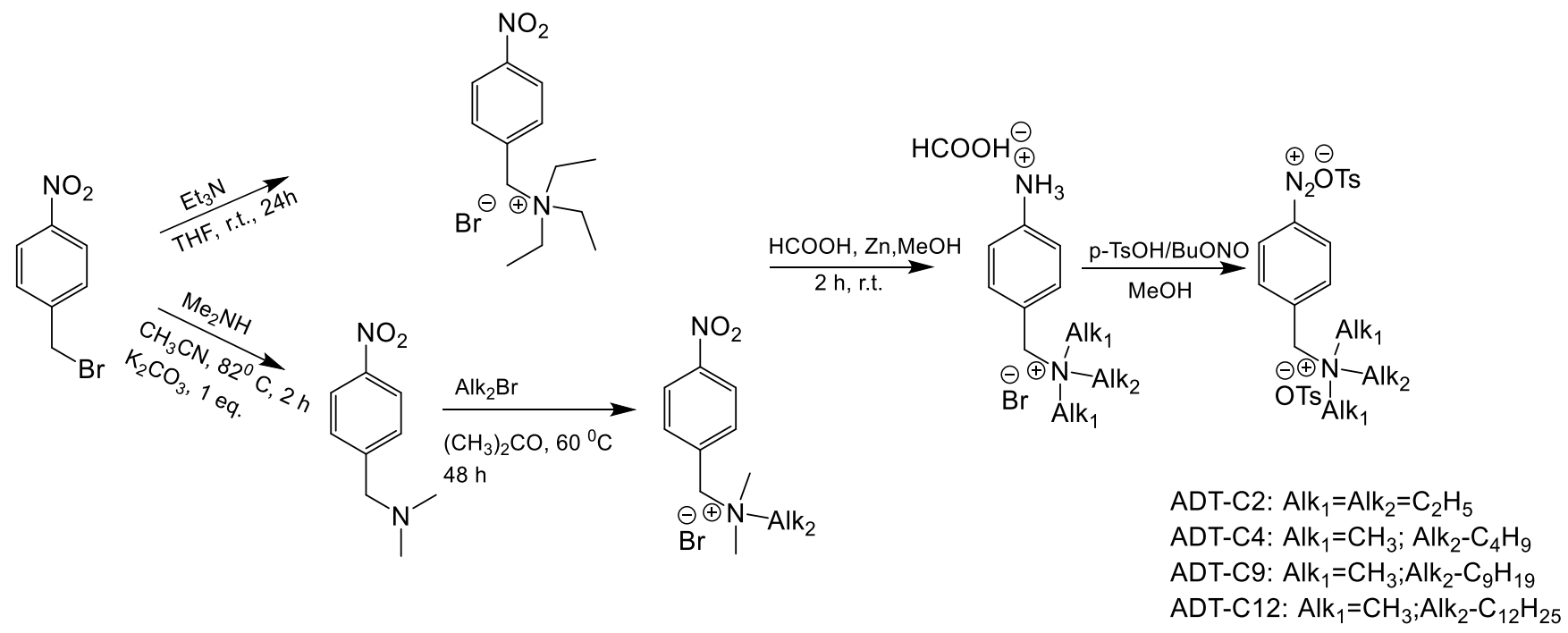

Figure 1. Preparation of ADT-C2, $\mathrm{C} 4, \mathrm{C} 9$ and $\mathrm{C} 12$ (the experimental procedures are provided in $\mathrm{SI})$.

The carbon dots (CDs) were prepared by a fast and facile microwave-assisted approach using citric acid as an environmentally-friendly carbon source and ethylenediamine [16,31] (Figure S1). The covalent modification by diazonium salts was carried out via simple mixing of CDs and ADT- $\mathrm{N}^{+} \mathrm{Alk}_{3}$ solutions under stirring and ultrasonication at room temperature. The resulting products were purified by dialysis (Figure 2). 


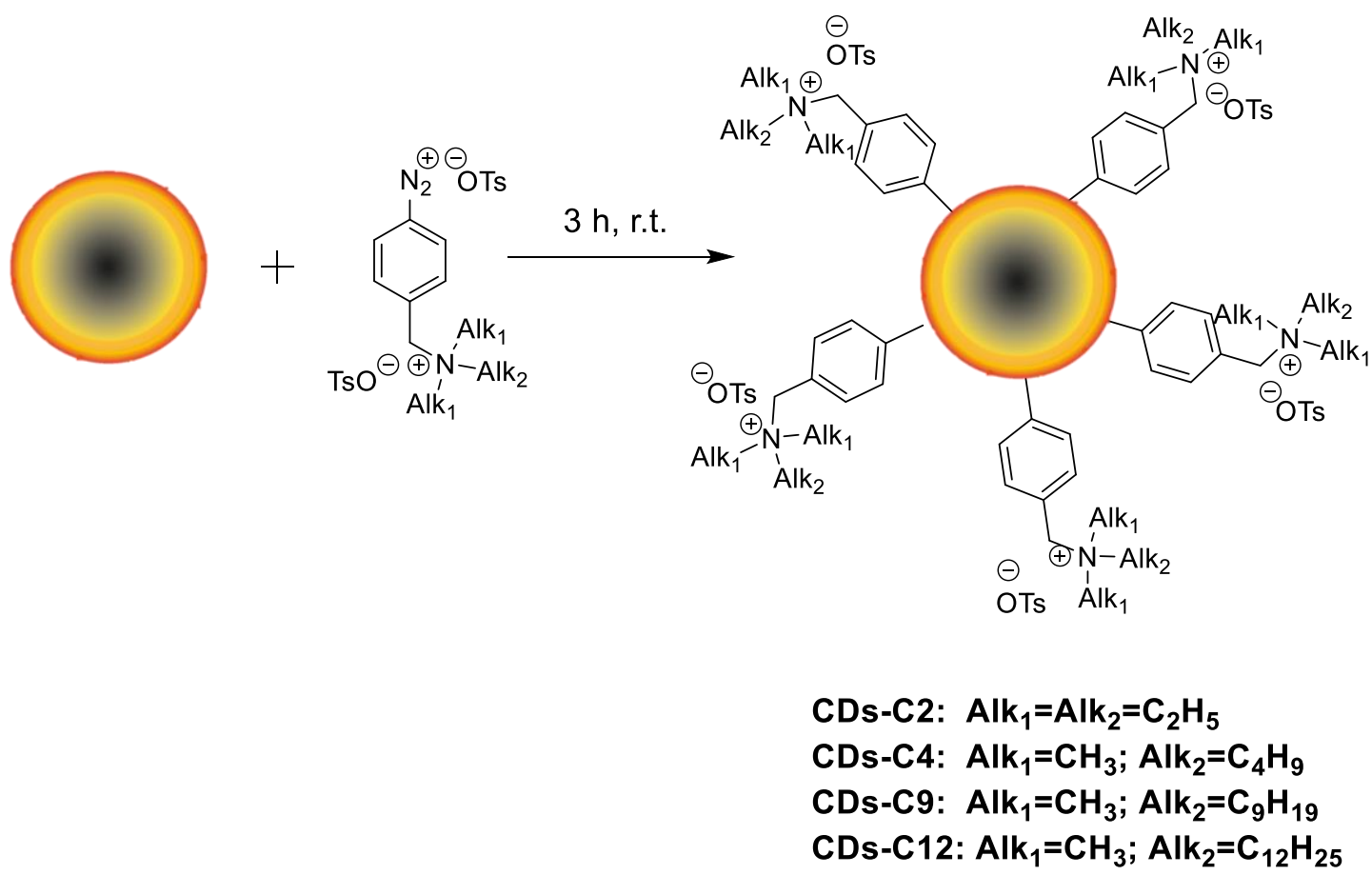

Figure 2. Preparation of CD-C2, CDs-C4, CDs-C9 and CDs-C12.

The surface modification by tetraalkylammonium moieties (TAA) was proved by Fouriertransform infrared (FTIR) spectroscopy and X-ray photoelectron spectroscopy (XPS). FTIR spectrum of pristine $\mathrm{CDs}$ revealed the presence of $\mathrm{C}=\mathrm{O} / \mathrm{N}-\mathrm{H}$ deformation $\left(1660 \mathrm{~cm}^{-1}\right), \mathrm{C}=\mathrm{C}\left(1560 \mathrm{~cm}^{-1}\right)$ and $\mathrm{C}$ $\mathrm{N}\left(1400 \mathrm{~cm}^{-1}\right)$ stretching vibrations, consistent with previously reported data [16]. After surface modification, the FTIR spectrum of modified CDs showed the appearance of novel vibration bands associated with covalent attachment of TAA groups: vibrations of alkyl chain (2930-2850, 1360, 685 $\left.\mathrm{cm}^{-1}\right)$, aromatic ring breathing modes $\left(685,1000,1124,1183 \mathrm{~cm}^{-1}\right)$ and tosylate anion $(685,1033$, 1124, $1183 \mathrm{~cm}^{-1}$ ) (Figure 3A, Figure S2, Table S1) [32]. The absence of a vibration band at 2300$2230 \mathrm{~cm}^{-1}\left(\mathrm{~N} \equiv \mathrm{N}^{+}\right)$indicates the absence of chemisorbed diazonium cations (Figure 3A, Figure S2). 


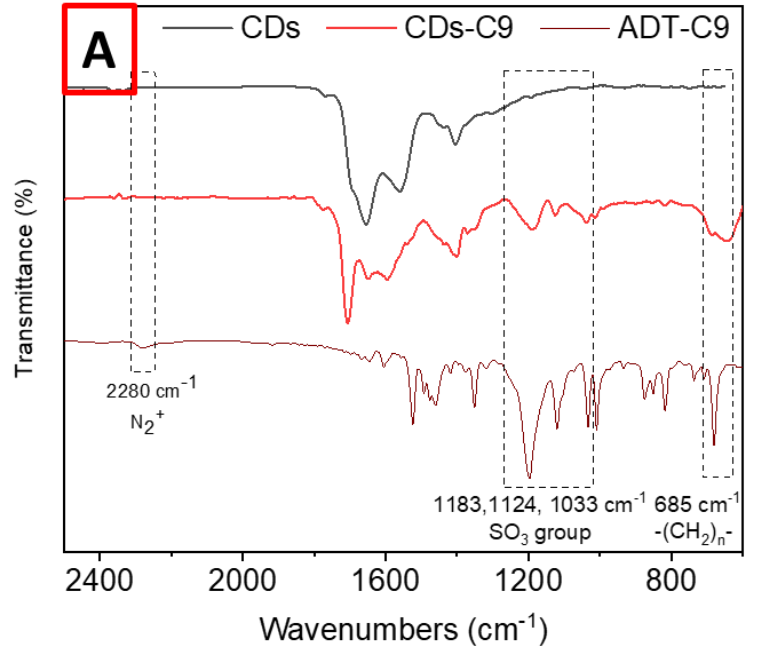

CDs
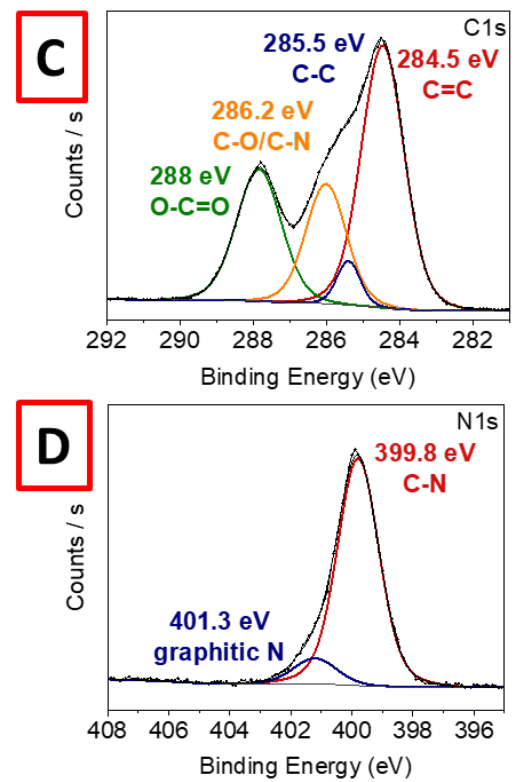

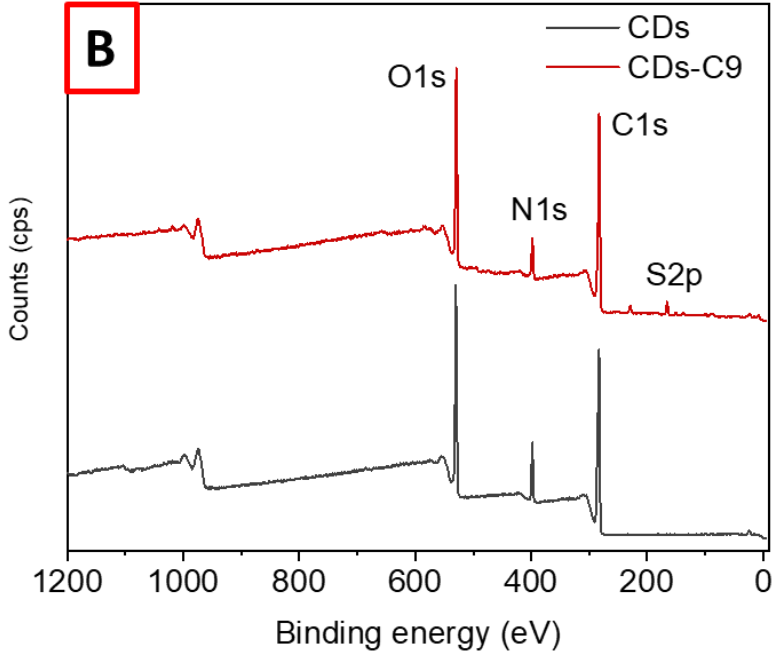

CDs-C9
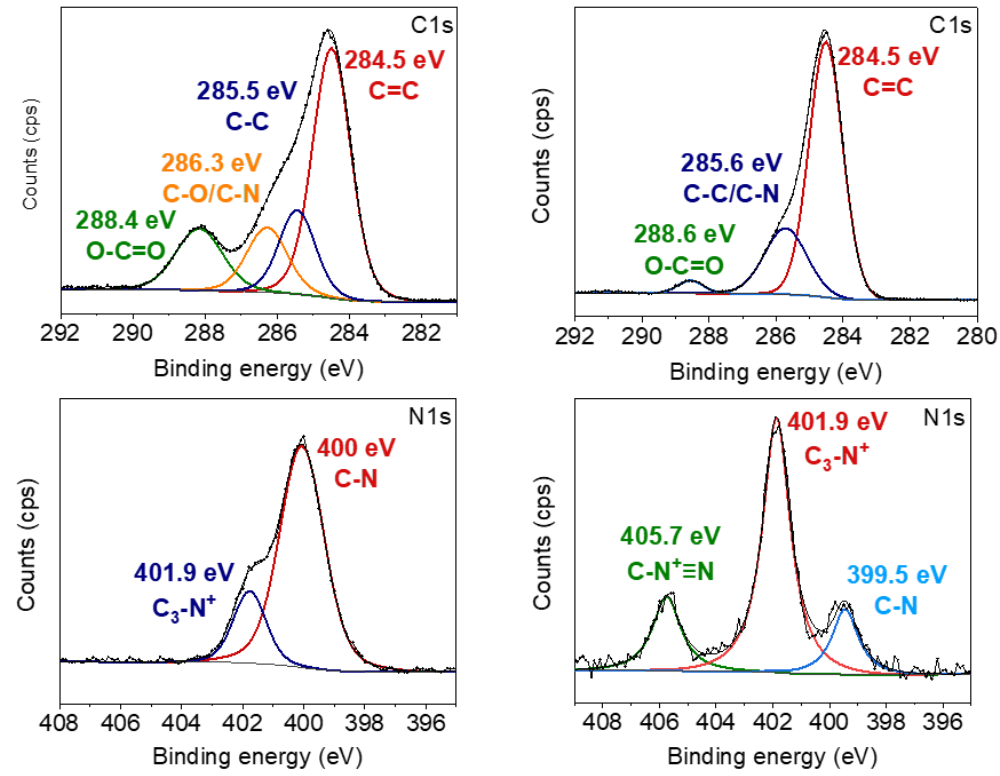

ADT-C9

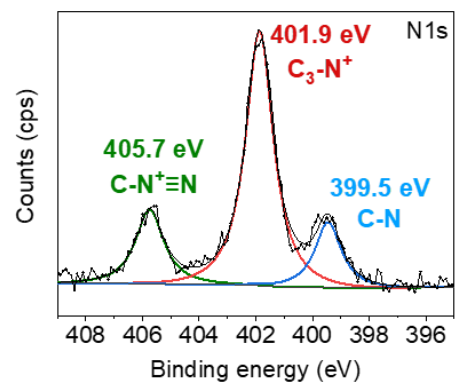

Figure 3. (A) FTIR spectra of CDs, CDs-C9 and ADT-C9, (B) XPS survey spectra of CDs and CDC9, and (C) core level spectra of the $\mathrm{C}_{1 \mathrm{~s}}$ of CDs, CDs-C9 and ADT-C9, and (D) $\mathrm{N}_{1 \mathrm{~s}}$ of CDs, CDsC9 and ADT-C9.

The chemical composition of the pristine and modified CDs was evaluated by XPS analysis (Figure 3B). The XPS survey spectrum of pristine CDs displays several peaks at 284.5, 400.0, and $531.0 \mathrm{eV}$ assigned respectively to $\mathrm{C}_{1 \mathrm{~s}}, \mathrm{~N}_{1 \mathrm{~s}}$ and $\mathrm{O}_{1 \mathrm{~s}}$. Compared to pristine $\mathrm{CDs}$, the XPS survey spectra of the modified CDs feature additional peaks due to $S_{2 p}$ and $S_{2 s}$ at 167.5 and $229.0 \mathrm{eV}$, respectively, associated with counterion $\mathrm{TsO}^{-}$of tetraalkylammonium moieties (Figures 3B, S3, Table S2) [33]. The deconvolution of the $\mathrm{C}_{1 \mathrm{~s}}$ peak allows to identify four components ascribed to $\mathrm{C}=\mathrm{C} / \mathrm{sp}^{2}(284.5 \mathrm{eV})$, $\mathrm{C}-\mathrm{C}(285.5 \mathrm{eV}), \mathrm{C}-\mathrm{O} / \mathrm{C}-\mathrm{N}(286.5 \mathrm{eV})$ and $\mathrm{O}-\mathrm{C}=\mathrm{O}(288.5 \mathrm{eV})$ (Figure 3C). Moreover, diazonium 
modification leads to an increase of the $\mathrm{C}-\mathrm{C}$ component at $285.5 \mathrm{eV}$ from $\approx 3$ to $\approx 12$ at. $\%$ and $\mathrm{C}=\mathrm{C}$ at $284.5 \mathrm{eV}$ for all modified CDs. The deconvolution of the $\mathrm{N}_{1 \mathrm{~s}}$ peak (Figure 3D) allows to identify the $\mathrm{C}-\mathrm{N}$ and $\mathrm{C}_{3}-\mathrm{N}^{+}$groups at 400.0 and $401.7 \mathrm{eV}$, respectively. While pristine $\mathrm{CDs}$ do not feature $\mathrm{C}_{3}-\mathrm{N}^{+}$ component, grafting of ADTs-C2-C12 results in its growth up to 1.8 at.\%, clearly indicating the presence of TAA groups in the structure of the modified CDs (Table S2). The highest increase of C$\mathrm{N}, \mathrm{C}=\mathrm{C}$ and $\mathrm{C}_{3}-\mathrm{N}^{+}$components and $\mathrm{S}_{2 \mathrm{p}}$ concentrations was observed for CDs-C2 and CDs-C9 (Table S2). Additional confirmation of covalent grafting of ADTs to CDs is the disappearance of $\mathrm{C}-\mathrm{N} \equiv \mathrm{N}^{+}$ related peak at $405.7 \mathrm{eV}$ due to ADTs [21,28,34].

Additionally, all prepared materials have been characterized by optical methods, such as UV-vis and fluorescence spectroscopy (Figure S4). The UV-vis spectra of pristine CDs exhibited the common absorbance peaks at 253 and $341 \mathrm{~nm}$ due to the $\pi \rightarrow \pi^{*}$ transition of aromatic $\mathrm{C}=\mathrm{C}$ bond, $\mathrm{n} \rightarrow \pi^{*}$ transition of the $\mathrm{C}=\mathrm{O}$ and $\mathrm{C}=\mathrm{N}$ bonds, respectively [16] (Figure S4A). For the modified CDs, the appearance of a new broad peak at $450 \mathrm{~nm}$, ascribed to agglomeration of weak positively charged CDs (Table 1), represents an indirect proof of a new lower energy state from attached functional group [35] (Figure S4A). The fluorescence quantum yield (QY, $\Phi$ ) of pristine CDs is 0.21 as compared to that of quinine sulfate used as reference (QY, 0.54 in $0.1 \mathrm{M} \mathrm{H}_{2} \mathrm{SO}_{4}$ ) (Figure S4C). The surface modification suppresses sufficiently the fluorescence, as reported earlier [36] (Figure S4B,C). The apparent decrease of the fluorescence peak intensity at $448 \mathrm{~nm}$ under $358 \mathrm{~nm}$ excitation for the modified CDs compared to pristine is due to the formation of surface layer after modification (Figure S4B).

The fluorescence spectra taken at excitations from 320 to $400 \mathrm{~nm}$ exhibit an excitation ( $\lambda_{\text {ex }}$ )independent emission $\left(\lambda_{\mathrm{em}}\right)$ behavior, which may originate from the narrow distribution of several key parameters such as surface defects, band gap, surface structure and diameter size [37,38]. The location of the fluorescence excitation and emission peaks for all modified CDs was slightly blue-shifted and also expressed in higher intensity at an excitation of $340 \mathrm{~nm}$ than at $360 \mathrm{~nm}$ (Figure S5). The shift in fluorescence emission peaks after functionalization originates from the bandgap tuning of the CDs after modification, which is probably due to the formation of new energy levels within the existing band gap structure $[39,40]$.

In addition to chemical and optical characterization, we studied the geometrical and hydrodynamic size of prepared materials by AFM and DLS measurements (Table 1, Figures S6, S7). Both methods demonstrated the apparent increase of particles' size upon increasing the alkyl chain length. A significant drop was observed only for CDs-C12 for which the hydrodynamic and geometrical 
diameters were similar to those of CDs-C2 and CDs-C4. This fact can be explained by the conformational freedom of long alkyl chain, which can form relatively dense structures in water or on substrates. The attachment of TAA moieties led to a pronounced change of the zeta potential of the pristine CDs from negative value to positive (Table 1), facilitating the interaction of modified CDs with negatively charged cell membranes [15,41].

Table 1. $\zeta$-potential and size of CDs and modified CDs.

\begin{tabular}{|c|c|c|c|c|}
\hline & Structure & $\begin{array}{c}\text { ל-potential, } \\
\mathrm{mV}\end{array}$ & $\begin{array}{c}\text { diameter }{ }^{\mathrm{a}}, \\
\mathbf{n m}\end{array}$ & $\begin{array}{l}\text { hydrodynamic } \\
\text { diameter }^{\mathrm{b}}, \mathrm{nm}\end{array}$ \\
\hline CDs & & $-13.0 \pm 3.0$ & $2.3 \pm 0.3$ & $7.3 \pm 1.7$ \\
\hline CDs-C2 & & $+2.7 \pm 2.3$ & $4.0 \pm 0.8$ & $109.9 \pm 39.4$ \\
\hline CDs-C4 & & $+4.7 \pm 2.5$ & $5.5 \pm 0.8$ & $72.1 \pm 20.5$ \\
\hline CDs-C9 & & $+7.5 \pm 2.0$ & $6.5 \pm 1.0$ & $130.2 \pm 60.8$ \\
\hline CDs-C12 & & $+13.0 \pm 3.0$ & $3.5 \pm 1.2$ & $103.7 \pm 18.7$ \\
\hline
\end{tabular}

${ }^{\mathrm{a}}$ according to AFM measurements on mica substrate (Figure S6); ${ }^{\mathrm{b}}$ size distribution by intens ity according to DLS measurements (Figure S7).

\subsection{Antimicrobial properties and cytotoxicity towards Staphylococcus aureus and Escherichia coli}

The antimicrobial activity of the pristine and modified CDs was assessed by the broth minimum inhibitory concentration (MIC) test using Gram-positive Staphylococcus aureus ATCC® $43300^{\mathrm{TM}}(S$. aureus) and Gram-negative bacteria Escherichia coli K12 MG 1566. (E. coli). The evaluation of MIC showed that pristine CDs did not affect the bacterial growth as expected [16] (Figure 4A, Table S3). 
The covalent attachment of C2-alkyl chain (CDs-C2) as well as C4-alkyl chain (CDs-C4) did not alter the antibacterial activity for both bacterial strains. This could be related to the weak positive surface charge $(+2.7 \pm 2.3$ and $+4.7 \pm 2.5 \mathrm{mV}$, respectively) and relatively low ability of short alkyl chains to interact with bacterial membrane (Table 1, Figure 4A), in agreement with previously reported results $[42,43]$. In the opposite, the presence of C9-moieties on the CDs' surface induced increased bacterial death with low MIC values for both strains $\left(3.09 \pm 1.10 \mu \mathrm{g} \mathrm{mL}^{-1}\right.$ for $S$. aureus and $7.93 \pm 0.17 \mu \mathrm{g} \mathrm{mL}^{-1}$ for E. coli) in comparison with previously reported data (Table S4). Further increase of the alkyl chain (CDs-C12) resulted in increased MIC values, owing to the capability of hydrophobic tails of adhering to one another via hydrophobic intermolecular interactions, blocking the electrostatic interactions of positively charged TAA with bacteria and diminishing the antibacterial potency. These findings are in good agreement with previous studies of relationship between alkyl length of tetraalkylammo nium salts and antibacterial activity of surface-modified materials [44-50].

Despite high antibacterial activity, biocompatibility of CDs is equally important. Previously, it has been reported that cationic polymers such as polyethylenimine (PEI) and derived carbon dots have a certain degree of toxicity, which stumbled their biomedical applications [48,51]. To investigate the biocompatibility of functionalized CDs-TAA, cytotoxicity study of pristine and modified CDs was performed on the mouse embryonic fibroblast 3T3-L1, HeLa (ATCC® CCL-2 ${ }^{\mathrm{TM}}$ ), and hypodiploid human (U-87 MG ATCC $®$ HTB-14 ${ }^{\mathrm{TM}}$ ) cell lines using MTT and resazurin assay, respectively (Figure 4B, Figure S8). In case of mouse embryonic fibroblast 3T3-L1 cell line, there is a tendency for an increase of the toxic effect upon increasing the alkyl chain length from $\mathrm{C} 2$ to $\mathrm{C} 12$, but low cytotoxicity was observed for CD-C9 in the 4-32 $\mu \mathrm{g} \mathrm{mL}^{-1}$ concentration range, which is higher than CDs-C9 MIC value (Figure 4B). After incubation with CDs modified with alkyldiazonium salts of different chain lengths for $24 \mathrm{~h}$ at concentrations up to $25 \mu \mathrm{g} \mathrm{mL} \mathrm{m}^{-1}$, the viability of HeLa cells (ATCC® CCL-2 ${ }^{\mathrm{TM}}$ ) and hypodiploid human (U-87 MG ATCC ${ }^{\circledR}$ HTB-14 ${ }^{\mathrm{TM}}$ ) was high and approaching 95\% for all CDs (Figure S8). In general, all CDs-TAA possess good biocompatibility and CDs-C9 with the optimal chain length can combat $S$. aureus and E. coli bacteria, thereby showing their great potential for antibiofilm applications. 


\begin{tabular}{|c|c|c|c|}
\hline \multirow{2}{*}{} & \multirow{2}{*}{$\begin{array}{c}\text { Alkyl } \\
\text { radical }\end{array}$} & \multicolumn{2}{|c|}{ MIC $\left(\mu \mathrm{mL}^{-1}\right)$} \\
\cline { 3 - 4 } & & S. aureus & E. coli \\
\hline CDs & - & $>256$ & $>256$ \\
\hline CDs-C2 & $\mathrm{C}_{2} \mathrm{H}_{5}$ & $>256$ & $>256$ \\
\hline CDs-C4 & $\mathrm{C}_{4} \mathrm{H}_{9}$ & $>256$ & $>256$ \\
\hline CDs-C9 & $\mathrm{C}_{9} \mathrm{H}_{19}$ & $\mathbf{3 . 0 9} \pm \mathbf{1 . 1 0}$ & $\mathbf{7 . 9 3} \pm \mathbf{0 . 1 7}$ \\
\hline CDs-C12 & $\mathrm{C}_{12} \mathrm{H}_{25}$ & 64 & 256 \\
\hline
\end{tabular}

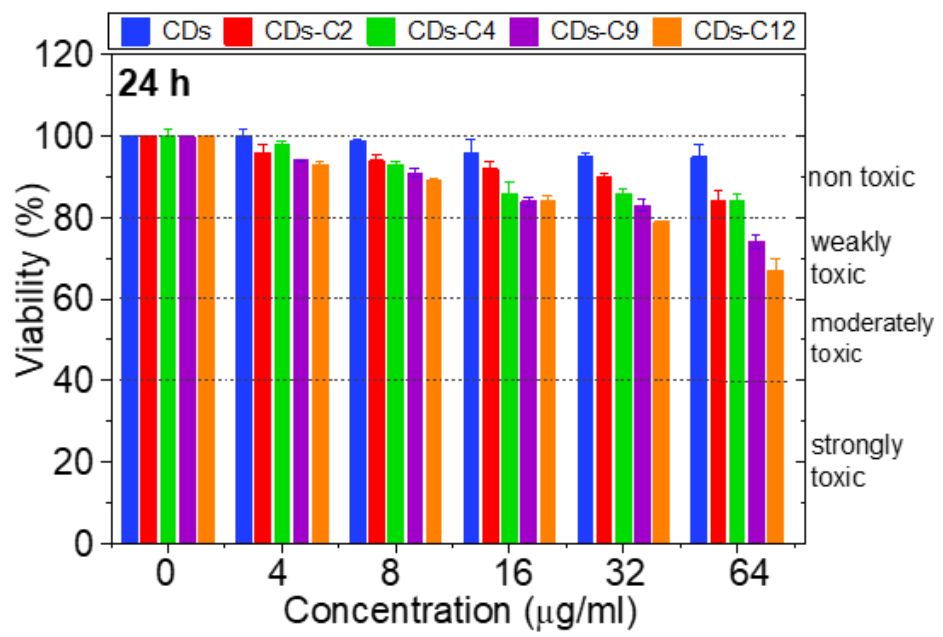

Table 2. MIC values of the CDs and modified CDs on S. aureus and E. coli;

Figure 4. Cell viability of 3T3-L1 cells after $24 \mathrm{~h}$ incubation with CDs, CDs-C2, CDs-C4, CDs-C9 and CDs-C12 at different concentrations determined using MTT assay.

The prepared CDs-C9 outperform most of previously reported CDs in terms of efficacy towards both Gram-positive and negative bacteria with low MIC values (Table S4). As was mentioned above, nitrogen-containing compounds are commonly used for the synthesis of antibacterial agents; however, involving alkylamines in hydrothermal synthesis does not provide high antibacterial properties $[9,16,52]$. In turn, utilization of nitrogen-containing polymers and quaternary ammonium compounds instead of alkylamines enhances the antibacterial properties of the resulting CDs only toward Grampositive bacteria and still insufficient toward Gram-negative bacteria [13,15,53-55]. The highest antimicrobial properties towards both bacteria was exhibited only by CDs synthesized from several nitrogen-containing components [14,56]. In comparison with discussed above approaches, covalent grafting of TAA to CDs provides low MIC values for both Gram-positive and negative bacteria combined with simple modification procedure.

\subsection{Biofilm destruction activity}

The formation of biofilms is one of the most effective mechanisms of resistance of bacterial cells, affecting the antibiotics and host's immune cells penetration and damage [2,57,58]. Previous studies have demonstrated that neutral and anionic CDs cannot penetrate or accumulate efficiently into biofilms [59]. In contrast, amphiphilic particles are able to readily penetrate biofilms [46]. Thus, we evaluated the antibacterial activity of CDs-C9 S. aureus and E. coli biofilms (Figure 5) in the concentration range of $0-256 \mu \mathrm{g} \mathrm{mL}-1$. The activity was investigated by a series of qualitative 
(live/dead fluorescence staining) and quantitative (crystal violet (CV) staining assay, spread plate method) methods. Based on published results of biofilm treatment (Table 3), we reduced the time of biofilms treatment from $24 \mathrm{~h}$ to 6 and $2 \mathrm{~h}$ to get closer to practical applications [14,60,61].
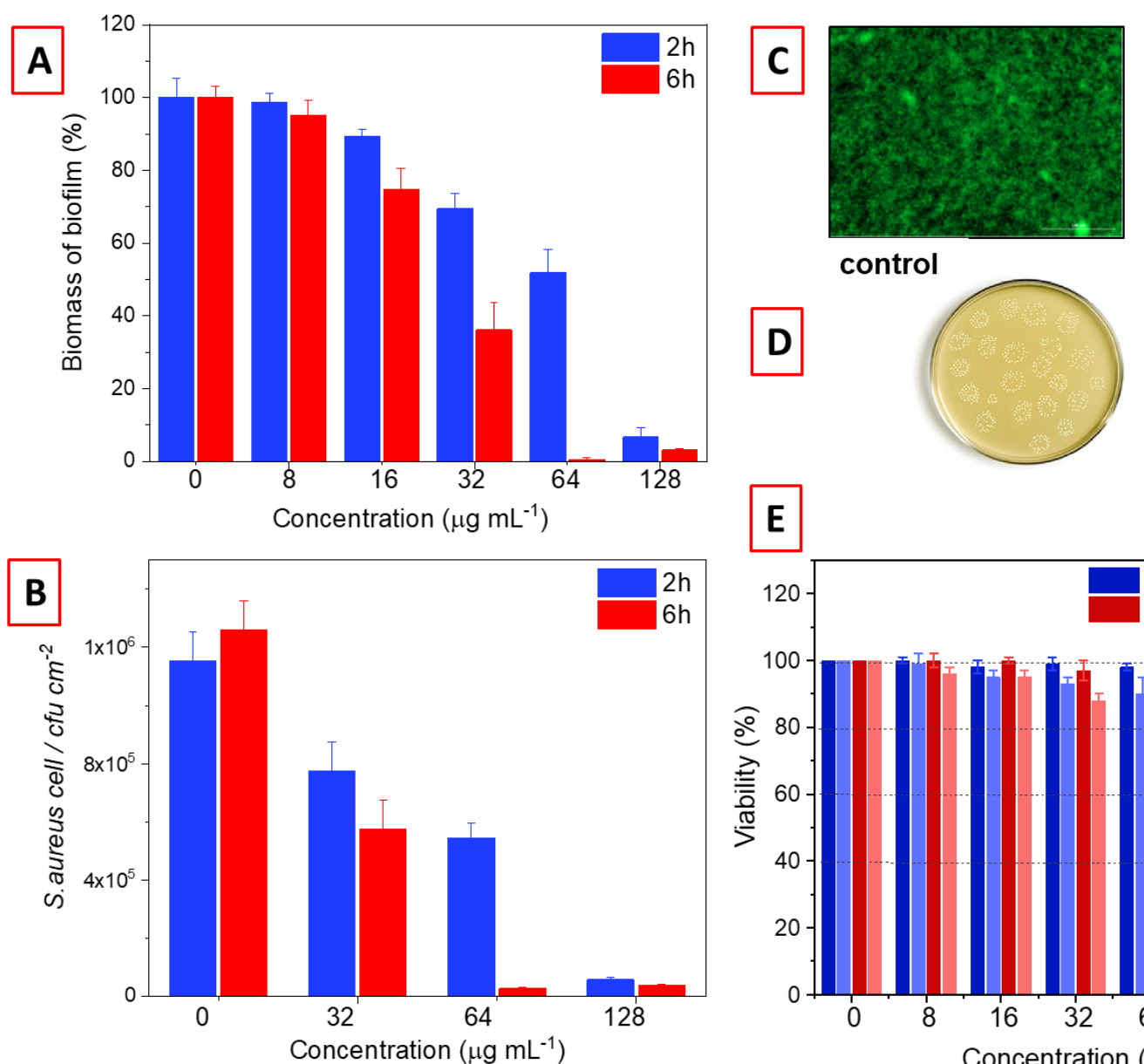

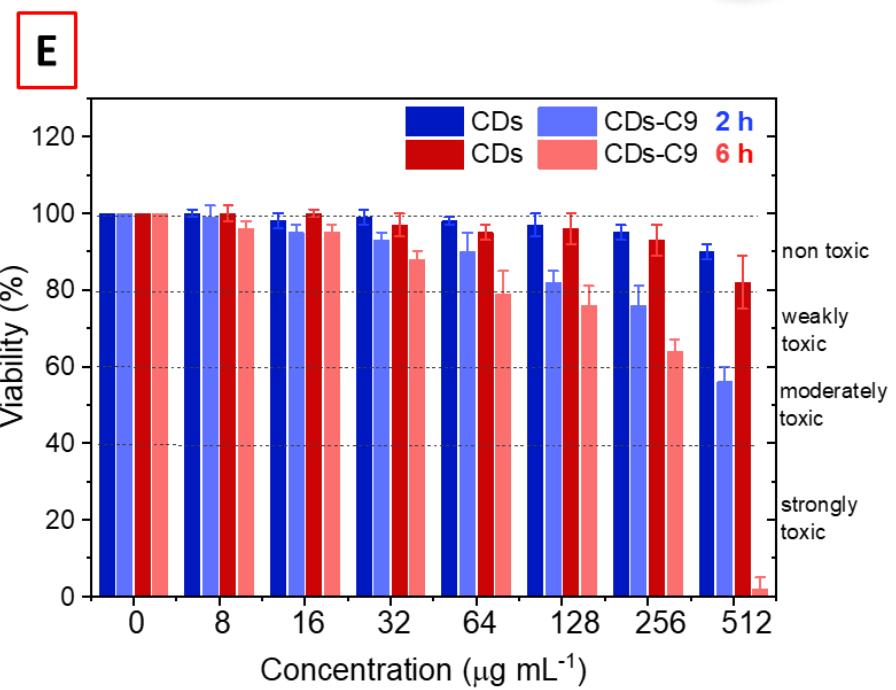

Figure 5. (A) Change of the S. aureus biomass as a function of CDs-C9 concentration after 2 and $6 \mathrm{~h}$ treatment. The biofilm biomass was quantified by the crystal violet (CV) absorbance (OD590nm) of the bacterial biofilms. The biomass of the intreated biofilm was set to be $100 \%$. (B) The bacterial survival rate of $S$. aureus in biofilms after 2 and $6 \mathrm{~h}$ treatment as a function of CDs-C9 concentration using the spread plate method. (C) Live/Dead imaged of untreated and treated biofilms for $6 \mathrm{~h}$. The bacteria are stained by green and red by SYTO 9/PI. The green and red colors stand for live and dead bacteria, respectively. (D) S. aureus colonies of bacteria in the biofilm before and after $6 \mathrm{~h}$ treatment at treatment at concentrations 0 and $64 \mu \mathrm{g} \mathrm{mL}^{-1}$. (E) Viability of 3T3-L1 cells treated with the pristine CDs and CDs-C9. 3T3-L1 cells were grown in 96-well plates $\left(10^{4}\right.$ cells/well) with $100 \mu \mathrm{L}$ of culture medium containing increasing concentration of CDs for $2 \mathrm{~h}$ (red) and $6 \mathrm{~h}$ (blue). The results, expressed 
as percentage of viability, are the mean value of two independent experiments with each treatment performed in triplicate. Negative control: without CDs.

The obtained results revealed that CDs-C9 could obstruct and destroy the biofilms of S. aureus in a dose-dependent way. Thus, incubation with CDs-C9 $(32 \mu \mathrm{g} \mathrm{mL}-1)$ led to $30 \%$ loss of the biofilm mass after $2 \mathrm{~h}$ and more than $60 \%$ after $6 \mathrm{~h}$ of treatment. The mass of the biofilms was less than $5 \%$ after treatment with CDs-C9 at $64 \mu \mathrm{g} \mathrm{mL} \mathrm{m}^{-1}$ for $6 \mathrm{~h}$ and at $128 \mu \mathrm{g} \mathrm{mL}-1$ for $2 \mathrm{~h}$ that also was proved by the colony formation results (Figure 5A, B). The bacterial viability of biofilms decreased with increasing CDs-C9 concentration (bacterial viability rate is $<10 \%$ at effective concentrations), and the above results are consistent with the results of crystal violet staining (Figure 5B). In addition, twodimensional confocal images of $S$. aureus biofilms stained using the LIVE/DEAD staining assay after $6 \mathrm{~h}$ treatment with different concentrations of CDs-C9 demonstrated only dead bacteria (red color) in contrast to live bacteria stained green (Figure 5C, D). In short, the obtained results suggest that CDC9 is a promising agent against $S$. aureus bacterial biofilms. In contrast, previously reported CDs usually require high CDs concentrations and longer treatment times (Table 2).

In addition, we evaluated the performance of CDs-C9 towards E. coli biofilms (Figure S9). After treatment for $6 \mathrm{~h}$ by CDs-C9, the biomass of the biofilms was lower than $35 \%$ at a concentration of $128 \mu \mathrm{g} \mathrm{mL}-1$ and less than $30 \%$ at a concentration of $256 \mu \mathrm{g} \mathrm{mL} \mathrm{m}^{-1}$, as determined by the colony formation assay. The weak cytotoxicity at these concentrations (Figure 5E) suggests the possibility of CD-C9 utilization not only in natural, industrial, and hospital settings also for the treatment of biofilm-related infections [62]. Although CDs-C9 demonstrated relatively lower activity towards Gram-negative bacterial biofilms, it was the highest among reported CD-based antibacterial materials [63] (Table 2).

Table 2. Comparison of antibiofilm performance of carbon quantum dots.

\begin{tabular}{|c|c|c|c|c|c|}
\hline $\begin{array}{c}\text { Antibiofilm } \\
\text { agent }\end{array}$ & $\begin{array}{c}\text { Bacteria } \\
\text { strains }\end{array}$ & $\begin{array}{c}\text { Biofilm } \\
\text { growth } \\
\text { conditions }\end{array}$ & $\begin{array}{c}\text { Time of } \\
\text { treatment } \\
(\mathrm{h})\end{array}$ & Working concentration $\left(\mu \mathrm{gL}^{-1}\right)$ & Ref. \\
\hline $\mathrm{CQD}_{2.5 \mathrm{w}}$ & S. aureus & $24 \mathrm{~h}$ & 24 & 250 & {$[53]$} \\
\hline N-CQDs & S. aureus & $48 \mathrm{~h}$ & 24 & $\begin{array}{c}20, \text { approximately 70\% (upper } \\
\text { concentration }- \text { toxic) }\end{array}$ & {$[14]$} \\
\hline $\mathrm{CQD}_{180}$ & S. aureus & $24 \mathrm{~h}$ & 24 & 80 & {$[60]$} \\
\hline
\end{tabular}




\begin{tabular}{|l|c|c|c|c|c|}
\hline \multirow{2}{*}{ CDs-C9 } & S. aureus & $72 \mathrm{~h}$ & $\mathbf{2}$ & $\mathbf{1 2 8}$ & \multirow{2}{*}{ Our work } \\
\cline { 4 - 5 } & & & $\mathbf{6}$ & $\mathbf{6 4}$ & \\
\cline { 4 - 5 } & E. coli & $120 \mathrm{~h}$ & $\mathbf{6}$ & $\begin{array}{c}\mathbf{2 5 6} \text { approximately 70\% bacteria } \\
\text { death }\end{array}$ & \\
\hline
\end{tabular}

The mechanism of enhanced antibacterial activity of CDs-C 9 can be explained by the optimal balance between two main factors: (i) the positive charge on the surface, increasing affinity towards cell membrane; and (ii) the hydrophobicity of alkyl chain, promoting penetration of CDs into the hydrophobic lipid layer of the cell membrane for its further damage.

\section{Conclusion}

In summary, a versatile functionalization protocol for the covalent attachment of tetraalkylammonium (TAA) moieties to carbon dots (CDs) surface via diazonium surface chemistry was demonstrated. Optimization of the alkyl chain length allowed to achieve a maximum antibacterial efficacy with low MIC values for Gram-positive S. aureus $(3.09 \pm 1.10 \mu \mathrm{g} \mathrm{mL}-1)$ and Gram-negative E. coli $\left(7.93 \pm 0.17 \mu \mathrm{g} \mathrm{mL}^{-1}\right)$. In addition, CDs-C9 was found to be an efficient agent for the treatment of $S$. aureus biofilms with a full inhibition at a concentration of $64 \mu \mathrm{g} \mathrm{mL} \mathrm{L}^{-1}$ after $6 \mathrm{~h}$ and at $128 \mu \mathrm{g}$ $\mathrm{mL}^{-1}$ after $2 \mathrm{~h}$ treatment. Furthermore, the developed material was able to suppress the growth of $E$. coli biofilm: treatment with CDs-C9 $(128 \mu \mathrm{g} \mathrm{mL}-1)$ for $6 \mathrm{~h}$ led to $>60 \%$ suppression of biofilm mass. The antibiofilm activity of CDs-C9 outperforms previously reported CDs in terms of treatment duration and minimal inhibitory concentration. The best antibacterial properties of CDs-C9 could be ascribed to the balance between the positive charge and hydrophobicity of the alkyl chains responsible of enhanced interaction with the negatively charged cell membrane and its subsequent damage. Besides, the most active CDs-C9 exhibited low cytotoxicity to three cell lines. Our findings provide new effective antimicrobial agent, but also offer an experimental strategy for investigation of structure- antimicrobial activity relationship.

\section{Declaration of competing interest}

The authors declare that they have no known competing financial interests or personal relationships that could have appeared to influence the work reported in this paper.

\section{Acknowledgments}


This work was supported by the by RFBR, project number 20-33-90042. Financial support from the Centre National de Recherche Scientifique (CNRS), the University of Lille, the Hauts-de-France region and the CPER "Photonics for Society" is acknowledged.

\section{Appendix A. Supporting information}

\section{References}

[1] https://www. who.int/news-room/fact-sheets/detail/antimicrobial-resistance.

[2] D. Sharma, L. Misba, A.U. Khan, Antibiotics versus biofilm: an emerging battleground in microbial communities, Antimicrob. Resist. Infect. Control 8 (2019) 76. https://doi.org/10.1186/s13756-019-0533-3.

[3] S. Szunerits, R. Boukherroub, Antibacterial activity of graphene-based materials, J. Mater. Chem. B 4 (2016) 6892-6912. https://doi.org/10.1039/C6TB01647B.

[4] N.-Y. Lee, W.-C. Ko, P.-R. Hsueh, Nanoparticles in the Treatment of Infections Caused by Multidrug-Resistant Organisms., Front. Pharmacol. $10 \quad$ (2019) 1153. https://doi.org/10.3389/fphar.2019.01153.

[5] Z.L. Shaw, S. Kuriakose, S. Cheeseman, M.D. Dickey, J. Genzer, A.J. Christofferson, R.J. Crawford, C.F. McConville, J. Chapman, V.K. Truong, A. Elbourne, S. Walia, Antipathoge nic properties and applications of low-dimensional materials, Nat. Commun. 12 (2021) 3897. https://doi.org/10.1038/s41467-021-23278-7.

[6] A. Ivask, T. Titma, M. Visnapuu, H. Vija, A. Kakinen, M. Sihtmae, S. Pokhrel, L. Madler, M. Heinlaan, V. Kisand, R.S. and A. Kahru, Toxicity of 11 Metal Oxide Nanoparticles to Three Mammalian Cell Types In V_itro, Curr. Top. Med. Chem. 15 (2015) 1914-1929. https://doi.org/http://dx.doi.org/10.2174/1568026615666150506150109.

[7] F. Yan, Y. Jiang, X. Sun, Z. Bai, Y. Zhang, X. Zhou, Surface modification and chemical functionalization of carbon dots: a review, Microchim. Acta 185 (2018) 424. https://doi.org/10.1007/s00604-018-2953-9.

[8] H. Feng, Z. Qian, Functional Carbon Quantum Dots: A Versatile Platform for Chemosensing and Biosensing, Chem. Rec. 18 (2018) 491-505. https $/ /$ doi.org/10.1002/tcr.201700055.

[9] D.I. Abu Rabe, M.M. Al Awak, F. Yang, P.A. Okonjo, X. Dong, L.R. Teisl, P. Wang, Y. Tang, N. Pan, Y.-P. Sun, L. Yang, The dominant role of surface functionalization in carbon dots' 
photo-activated antibacterial activity., Int. J. Nanomedicine 14 (2019) 2655-2665. https://doi.org/10.2147/IJN.S200493.

[10] H.-J. Jian, R.-S. Wu, T.-Y. Lin, Y.-J. Li, H.-J. Lin, S.G. Harroun, J.-Y. Lai, C.-C. Huang, SuperCationic Carbon Quantum Dots Synthesized from Spermidine as an Eye Drop Formulation for Topical Treatment of Bacterial Keratitis, ACS Nano 11 (2017) 6703-6716. https://doi.org/10.1021/acsnano.7b01023.

[11] N.A. Travlou, D.A. Giannakoudakis, M. Algarra, A.M. Labella, E. Rodríguez-Castellón, T.J. Bandosz, S- and N-doped carbon quantum dots: Surface chemistry dependent antibacterial activity, Carbon 135 (2018) 104-111. https://doi.org/10.1016/j.carbon.2018.04.018.

[12] Y.-J. Li, S.G. Harroun, Y.-C. Su, C.-F. Huang, B. Unnikrishnan, H.-J. Lin, C.-H. Lin, C.-C. Huang, Synthesis of Self-Assembled Spermidine-Carbon Quantum Dots Effective against Multidrug-Resistant Bacteria, Adv. Healthc. Mater. 5 (2016) 2545-2554. https://doi.org/10.1002/adhm.201600297.

[13] C. Zhao, L. Wu, X. Wang, S. Weng, Z. Ruan, Q. Liu, L. Lin, X. Lin, Quaternary ammonium carbon quantum dots as an antimicrobial agent against gram-positive bacteria for the treatment of MRSA-infected pneumonia in mice, Carbon 163 (2020) 70-84. https://doi.org/10.1016/j.carbon.2020.03.009.

[14] H. Wang, Z. Song, J. Gu, S. Li, Y. Wu, H. Han, Nitrogen-Doped Carbon Quantum Dots for Preventing Biofilm Formation and Eradicating Drug-Resistant Bacteria Infection, ACS Biomater. Sci. Eng. 5 (2019) 4739-4749. https://doi.org/10.1021/acsbiomaterials.9b00583.

[15] X. Hao, L. Huang, C. Zhao, S. Chen, W. Lin, Y. Lin, L. Zhang, A. Sun, C. Miao, X. Lin, M. Chen, S. Weng, Antibacterial activity of positively charged carbon quantum dots without detectable resistance for wound healing with mixed bacteria infection, Mater. Sci. Eng. C 123 (2021) 111971. https://doi.org/10.1016/j.msec.2021.111971.

[16] R. Jijie, A. Barras, J. Bouckaert, N. Dumitrascu, S. Szunerits, R. Boukherroub, Enhanced antibacterial activity of carbon dots functionalized with ampicillin combined with visible light triggered photodynamic effects., Colloids Surf. B $170 \quad$ (2018) 347-354. https://doi.org/10.1016/j.colsurfb.2018.06.040.

[17] K. Rajendiran, Z. Zhao, D.S. Pei, A. Fu, Antimicrobial activity and mechanism of $\begin{array}{llllll}\text { functionalized } & \text { quantum } & \text { dots, } & \text { Polymers } & 11 & \text { (2019) }\end{array}$ https://doi.org/10.3390/polym11101670.

[18] Q. Dou, X. Fang, S. Jiang, P.L. Chee, T.-C. Lee, X.J. Loh, Multi-functional fluorescent carbon 
dots with antibacterial and gene delivery properties, RSC Adv. 5 (2015) 46817-46822. https://doi.org/10.1039/C5RA07968C.

[19] C. Cao, Y. Zhang, C. Jiang, M. Qi, G. Liu, Advances on Aryldiazonium Salt Chemistry Based Interfacial Fabrication for Sensing Applications, ACS Appl. Mater. Interfaces 9 (2017) 50315049. https://doi.org/10.1021/acsami.6b16108.

[20] O. Guselnikova, P. Postnikov, R. Elashnikov, M. Trusova, Y. Kalachyova, M. Libansky, J. Barek, Z. Kolska, V. Švorčík, O. Lyutakov, Surface modification of Au and Ag plasmonic thin films via diazonium chemistry: Evaluation of structure and properties, Colloids Surf. A 516 (2017) 274-285. https://doi.org/https://doi.org/10.1016/j.colsurfa.2016.12.040.

[21] A.A. Mohamed, Z. Salmi, S.A. Dahoumane, A. Mekki, B. Carbonnier, M.M. Chehimi, Functionalization of nanomaterials with aryldiazonium salts, Adv. Colloid Interface Sci. 225 (2015) 16-36. https://doi.org/10.1016/j.cis.2015.07.011.

[22] A. Bensghaïer, F. Mousli, A. Lamouri, P.S. Postnikov, M.M. Chehimi, The Molecular and Macromolecular Level of Carbon Nanotube Modification Via Diazonium Chemistry: Emphasis on the 2010s Years, Chem. Africa 3 (2020) 535-569. https://doi.org/10.1007/s42250-02000144-5.

[23] A.A.L. Ahmad, J.B. Marutheri Parambath, P.S. Postnikov, O. Guselnikova, M.M. Chehimi, M.R.M. Bruce, A.E. Bruce, A.A. Mohamed, Conceptual Developments of Aryldiazonium Salts as Modifiers for Gold Colloids and Surfaces, Langmuir 37 (2021) 8897-8907. https://doi.org/10.1021/acs. langmuir.1 c00884.

[24] P. Luo, Z. Ji, C. Li, G. Shi, Aryl-modified graphene quantum dots with enhanced photoluminescence and improved pH tolerance, Nanoscale 5 (2013) 7361. https://doi.org/10.1039/c3nr02156d.

[25] E. Hwang, H.M. Hwang, Y. Shin, Y. Yoon, H. Lee, J. Yang, S. Bak, H. Lee, Chemically modulated graphene quantum dot for tuning the photoluminescence as novel sensory probe, Sci. Rep. 6 (2016) 39448. https://doi.org/10.1038/srep39448.

[26] S. Baghi Sefidan, H. Eskandari, A.N. Shamkhali, Rapid colorimetric flow injection sensing of hypochlorite by functionalized graphene quantum dots, Sen. Actuators B 275 (2018) 339-349. https://doi.org/10.1016/j.snb.2018.08.023.

[27] C.A. Zuniga, J.B. Goods, J.R. Cox, T.M. Swager, Long-Term High-Temperature Stability of Functionalized Graphene Oxide Nanoplatelets in Arab-D and API Brine, ACS Appl. Mater. Interfaces 8 (2016) 1780-1785. https://doi.org/10.1021/acsami.5b09656. 
[28] S. Kesavan, S.A. John, A novel approach to fabricate stable graphene layers on electrode surfaces using simultaneous electroreduction of diazonium cations and graphene oxide, RSC Adv. 6 (2016) 62876-62883. https://doi.org/10.1039/C6RA15821H.

[29] H. Tetsuka, A. Nagoya, T. Fukusumi, T. Matsui, Molecularly Designed, NitrogenFunctionalized Graphene Quantum Dots for Optoelectronic Devices, Adv. Mater. 28 (2016) 4632-4638. https://doi.org/10.1002/adma.201600058.

[30] V.D. Filimonov, M. Trusova, P. Postnikov, E.A. Krasnokutskaya, Y.M. Lee, H.Y. Hwang, H. Kim, K.-W. Chi, Unusually Stable, Versatile, and Pure Arenediazonium Tosylates: Their Preparation, Structures, and Synthetic Applicability, Org. Lett. 10 (2008) 3961-3964. https://doi.org/10.1021/o18013528.

[31] C.O. Kappe, Controlled Microwave Heating in Modern Organic Synthesis, Angew. Chem. Int. Ed. 43 (2004) 6250-6284. https//doi.org/10.1002/anie.200400655.

[32] F. Mirkhalaf, J. Paprotny, D.J. Schiffrin, Synthesis of Metal Nanoparticles Stabilized by Metal-Carbon Bonds, J. Am. Chem. Soc. 128 (2006) 7400-7401. https://doi.org/10.1021/ja058687g.

[33] H. Wang, P. Sun, S. Cong, J. Wu, L. Gao, Y. Wang, X. Dai, Q. Yi, G. Zou, Nitrogen-doped carbon dots for "green" quantum dot solar cells, Nanoscale Res. Lett. 11 (2016) 1-6. https://doi.org/10.1186/s11671-016-1231-1.

[34] A. Blacha-Grzechnik, K. Piwowar, P. Koscielniak, M. Kwoka, J. Szuber, J. Zak, Phenothiazines grafted on the electrode surface from diazonium salts as molecular layers for photochemical generation of singlet oxygen, Electrochim. Acta 182 (2015) 1085-1092. https://doi.org/10.1016/j.electacta.2015.10.017.

[35] Carbonaro, Corpino, Salis, Mocci, Thakkar, Olla, Ricci, On the Emission Properties of Carbon Dots: Reviewing Data and Discussing Models, C - J. Carbon Res. 5 (2019) 60. https://doi.org/10.3390/c5040060.

[36] B. Bin Chen, M.L. Liu, C.M. Li, C.Z. Huang, Fluorescent carbon dots functionalization, Adv. Colloid Interface Sci. 270 (2019) 165-190. https://doi.org/10.1016/j.cis.2019.06.008.

[37] S. Zhu, Y. Song, X. Zhao, J. Shao, J. Zhang, B. Yang, The photoluminescence mechanism in carbon dots (graphene quantum dots, carbon nanodots, and polymer dots): current state and future perspective, Nano Res. 8 (2015) 355-381. https://doi.org/10.1007/s12274-014-0644-3.

[38] H. Ding, X.-H. Li, X.-B. Chen, J.-S. Wei, X.-B. Li, H.-M. Xiong, Surface states of carbon dots and their influences on luminescence, J. Appl. Phys. 127 (2020) 231101. 
https://doi.org/10.1063/1.5143819.

[39] U. Baruah, M.J. Deka, D. Chowdhury, Reversible on/off switching of fluorescence via esterification of carbon dots, RSC Adv. 4 (2014) 36917. https://doi.org/10.1039/C4RA04734F.

[40] G. Sandeep Kumar, R. Roy, D. Sen, U.K. Ghorai, R. Thapa, N. Mazumder, S. Saha, K.K. Chattopadhyay, Amino-functionalized graphene quantum dots: origin of tunable heterogeneous photoluminescence, Nanoscale 6 (2014) 3384. https://doi.org/10.1039/c3nr05376h.

[41] T.J. Silhavy, D. Kahne, S. Walker, The Bacterial Cell Envelope, Cold Spring Harb. Perspect. Biol. 2 (2010) a000414-a000414. https//doi.org/10.1101/cshperspect.a000414.

[42] F. Li, M.D. Weir, H.H.K. Xu, Effects of Quaternary Ammonium Chain Length on Antibacterial Bonding Agents, J. Dent. Res. $92 \quad$ (2013) 932-938. https://doi.org/10.1177/0022034513502053.

[43] K. Zhang, L. Cheng, M.D. Weir, Y.-X. Bai, H.H. Xu, Effects of quaternary ammonium chain length on the antibacterial and remineralizing effects of a calcium phosphate nanocomposite, Int. J. Oral Sci. 8 (2016) 45-53. https://doi.org/10.1038/ijos.2015.33.

[44] X. Lv, C. Liu, S. Song, Y. Qiao, Y. Hu, P. Li, Z. Li, S. Sun, Construction of a quaternary ammonium salt platform with different alkyl groups for antibacterial and biosensor applications, RSC Adv. 8 (2018) 2941-2949. https://doi.org/10.1039/C7RA11001D.

[45] S. V. Sapozhnikov, A.E. Sabirova, N. V. Shtyrlin, A.Y. Druk, M.N. Agafonova, M.N. Chirkova, R.R. Kazakova, D.Y. Grishaev, T. V. Nikishova, E.S. Krylova, E. V. Nikitina, A.R. Kayumov, Y.G. Shtyrlin, Design, synthesis, antibacterial activity and toxicity of novel quaternary ammonium compounds based on pyridoxine and fatty acids, Eur. J. Med. Chem. 211 (2021) 113100. https://doi.org/10.1016/j.ejmech.2020.113100.

[46] A. Chen, A. Karanastasis, K.R. Casey, M. Necelis, B.R. Carone, G.A. Caputo, E.F. Palermo, Cationic Molecular Umbrellas as Antibacterial Agents with Remarkable Cell-Type Selectivity, ACS Appl. Mater. $\quad$ Interfaces $12 \quad$ (2020) 21270-21282. https://doi.org/10.1021/acsami.9b19076.

[47] M. Benkova, O. Soukup, L. Prchal, R. Sleha, T. Eleršek, M. Novak, K. Sepčić, N. GundeCimerman, R. Dolezal, V. Bostik, P. Bostik, J. Marek, Synthesis, Antimicrobial Effect and Lipophilicity-Activity Dependence of Three Series of Dichained N -Alkylammonium Salts, ChemistrySelect 4 (2019) 12076-12084. https//doi.org/10.1002/slct.201902357.

[48] P.Y.M. Yew, P.L. Chee, O. Cally, K. Zhang, S.S. Liow, X.J. Loh, Quarternized Short Polyethylenimine Shows Good Activity against Drug-Resistant Bacteria, Macromol. Mater. 
Eng. 302 (2017) 1700186. https://doi.org/10.1002/mame.201700186.

[49] H.-W. Chien, Y.-Y. Chen, Y.-L. Chen, C.-H. Cheng, J.-C. Lin, Studies of PET nonwovens modified by novel antimicrobials configured with both $\mathrm{N}$-halamine and dual quaternary ammonium with different alkyl chain length, RSC Adv. 9 (2019) 7257-7265. https://doi.org/10.1039/C9RA00094A.

[50] M. Chrószcz, I. Barszczewska-Rybarek, Nanoparticles of Quaternary Ammonium Polyethylenimine Derivatives for Application in Dental Materials, Polymers 12 (2020) 2551. https://doi.org/10.3390/polym12112551.

[51] M. Havrdova, K. Hola, J. Skopalik, K. Tomankova, M. Petr, K. Cepe, K. Polakova, J. Tucek, A.B. Bourlinos, R. Zboril, Toxicity of carbon dots - Effect of surface functionalization on the cell viability, reactive oxygen species generation and cell cycle, Carbon 99 (2016) 238-248. https://doi.org/10.1016/j.carbon.2015.12.027.

[52] F. Du, S. Shuang, Z. Guo, X. Gong, C. Dong, M. Xian, Z. Yang, Rapid synthesis of multifunctional carbon nanodots as effective antioxidants, antibacterial agents, and quercetin nanoprobes, Talanta 206 (2020) 120243. https://doi.org/10.1016/j.talanta.2019.120243.

[53] P. Li, X. Yang, X. Zhang, J. Pan, W. Tang, W. Cao, J. Zhou, X. Gong, X. Xing, Surface chemistry-dependent antibacterial and antibiofilm activities of polyamine-functionalized carbon quantum dots, J. Mater. Sci. 55 (2020) 16744-16757. https://doi.org/10.1007/s10853020-05262-6.

[54] S. Demirci, A.B. McNally, R.S. Ayyala, L.B. Lawson, N. Sahiner, Synthesis and characterization of nitrogen-doped carbon dots as fluorescent nanoprobes with antimicrobial properties and skin permeability, J. Drug Deliv. Sci. Technol. 59 (2020) 101889. https://doi.org/10.1016/j.jddst.2020.101889.

[55] J. Yang, G. Gao, X. Zhang, Y.-H. Ma, X. Chen, F.-G. Wu, One-step synthesis of carbon dots with bacterial contact-enhanced fluorescence emission: Fast Gram-type identification and selective Gram-positive bacterial inactivation, Carbon 146 (2019) 827-839. https://doi.org/10.1016/j.carbon.2019.02.040.

[56] M. Gagic, S. Kociova, K. Smerkova, H. Michalkova, M. Setka, P. Svec, J. Pribyl, J. Masilko, R. Balkova, Z. Heger, L. Richtera, V. Adam, V. Milosavljevic, One-pot synthesis of natural amine-modified biocompatible carbon quantum dots with antibacterial activity, J. Colloid Interface Sci. 580 (2020) 30-48. https://doi.org/10.1016/j.jcis.2020.06.125.

[57] D. Lebeaux, J.-M. Ghigo, C. Beloin, Biofilm-Related Infections: Bridging the Gap between 
Clinical Management and Fundamental Aspects of Recalcitrance toward Antibiotics, Microbiol. Mol. Biol. Rev. 78 (2014) 510-543. https://doi.org/10.1128/MMBR.00013-14.

[58] J.M. V. Makabenta, A. Nabawy, C.-H. Li, S. Schmidt-Malan, R. Patel, V.M. Rotello, Nanomaterial-based therapeutics for antibiotic-resistant bacterial infections, Nat. Rev. Microbiol. 19 (2021) 23-36. https://doi.org/10.1038/s41579-020-0420-1.

[59] X. Li, Y.-C. Yeh, K. Giri, R. Mout, R.F. Landis, Y.S. Prakash, V.M. Rotello, Control of nanoparticle penetration into biofilms through surface design, Chem. Commun. 51 (2015) 282285. https://doi.org/10.1039/C4CC07737G.

[60] P. Li, S. Liu, W. Cao, G. Zhang, X. Yang, X. Gong, X. Xing, Low-toxicity carbon quantum dots derived from gentamicin sulfate to combat antibiotic resistance and eradicate mature biofilms, Chem. Commun. 56 (2020) 2316-2319. https://doi.org/10.1039/C9CC09223D.

[61] H.-H. Ran, X. Cheng, Y.-W. Bao, X.-W. Hua, G. Gao, X. Zhang, Y.-W. Jiang, Y.-X. Zhu, F.G. $\mathrm{Wu}$, Multifunctional quaternized carbon dots with enhanced biofilm penetration and eradication efficiencies, J. Mater. Chem. B 7 (2019) 5104-5114. https://doi.org/10.1039/C9TB00681H.

[62] L. Hall-Stoodley, J.W. Costerton, P. Stoodley, Bacterial biofilms: from the Natural environment to infectious diseases, Nat. Rev. Microbiol. 2 (2004) 95-108. https://doi.org/10.1038/nrmicro821.

[63] F. Lin, C. Li, L. Dong, D. Fu, Z. Chen, Imaging biofilm-encased microorganisms using carbon dots derived from L. plantarum, Nanoscale 9 (2017) 9056-9064. https://doi.org/10.1039/C7NR01975K. 